\title{
A Customer Retention System Based on the Customer Intelligence for A Telecom Company
}

\author{
Tong $\mathrm{Li}^{1}$ Peng Lu ${ }^{2}$ Zhilong He ${ }^{1}$ Qiang Wang ${ }^{1}$ \\ ${ }^{1}$ College of Management, Shenzhen University, Shenzhen, P.R.China, 518060 \\ ${ }^{2}$ Shenzhen Scitel Digital Ltd., Shenzhen Hi Park, W1-B, 5/F, P.R.China, 518057
}

\begin{abstract}
Global competition is fierce. Especially, it is in the telecom market. It is a more and more difficult task for retaining profitable customers for a telecom company. In this paper, a retention system based on the customer intelligence is introduced. The system was successfully used for one telecom company in China to get 'how to' for effective retention.
\end{abstract}

Keywords: Customer Retention, Customer churn, Customer Intelligence, Machine Learning $\backslash$ Data Mining.

\section{Introduction}

In the telecom industry, customers are able to choose among multiple service providers and actively exercise their rights of switching from one service provider to another. Now, the same situations are in China after China's WTO entry. In this fiercely competitive market, customers demand tailored products and better services at lower prices, while service providers constantly focus on acquisitions as their business goals. Given the fact that the telecom industry experiences an average of 25-30 percent annual churn rate [1] and Gartner Group shows that it costs 5-10 times more to recruit a new customer than to retain an existing one, customer retention has now become even more important than customer acquisition. For many incumbent operators, retaining high profitable customers is the number one business pain.

In order to support telecom companies manage churn reduction, not only do we need to predict which customers are at high risk of churn, but also we need to know how soon these high-risk customers will churn. Therefore the telecom companies can optimize their marketing intervention resources to prevent as many customers as possible from churning. In other words, if the telecom companies know which customers are at high risk of churn and when they will churn, they are able to design customized customer communication and treatment programs in a timely efficient manner.

So, in this paper, the retention system based on the customer intelligence is introduced to get 'how to' for effective retention for a telecom company in China.

\section{The Customer Retention system Based on Customer Intelligence}

\subsection{Customer Intelligence and Machine Learning $\backslash$ Data Mining}

Customer Intelligence, here, means the set of methods and processes for getting and using customer knowledge. It can help companies to build and grow more profitable customer relationships.

With Customer Intelligence, companies can easily slice through volumes of complex customer, sales, and marketing data. They can also analyze key data to gain insight into call center activity and customer behavior or customer knowledge. The company will identify and retains the right customers at correct time by using the updating timely customer knowledge. Machine learning $\backslash$ Data mining techniques are very important tools in customer intelligence.

Machine Learning is the study of computer algorithms that improve automatically through experience. Applications range from data mining programs that discover general rules in large data sets, to information filtering systems that automatically learn users' interests [2].

Generally, the steps for building a model with Customer Intelligence as following:

- Problem Definition

- Data Collection /Preparation

- Data Preprocessing

- Feature Extraction/Input Selection

- Algorithm Selection

- Architecture/Training Parameters Selection

- Training /Testing

- Model Evaluation

- Model Deployment 


\subsection{Customer Retention}

Given today's marketplace demands, it is more important than ever for businesses to reduce customer turnover. To do that, you need a way to determine which of your customers are likely to leave - and which ones you want to keep - so you can execute marketing strategies to convince them to stay.

According to the report from Advance Marketing Consultant in www.marketingprinciples.com, reasons customers leave will be included as following [3]:

- Move or Die 4\%

- Other Company Friendship 5\%

- Competition 9\%

- Product Dissatisfaction 15\%

- No Customer Contact Strategy 67\%

From above, we can find that the primary reason for customer churn is 'no Customer contact Strategy'. Apparently, the next question will be which customers the company want or deserve to contact. The customer retention model based on intelligence enable to quickly gain an understanding of the variables that influence customer churn - allowing us to determine not only which customers are likely to leave, but why.

\subsection{A Customer Retention System Based on Customer Intelligence}

The customer retention system is a typical closed loop one. The results of customer treatment procedure for retention will be returned to the Source Database. See Fig 1 as below.

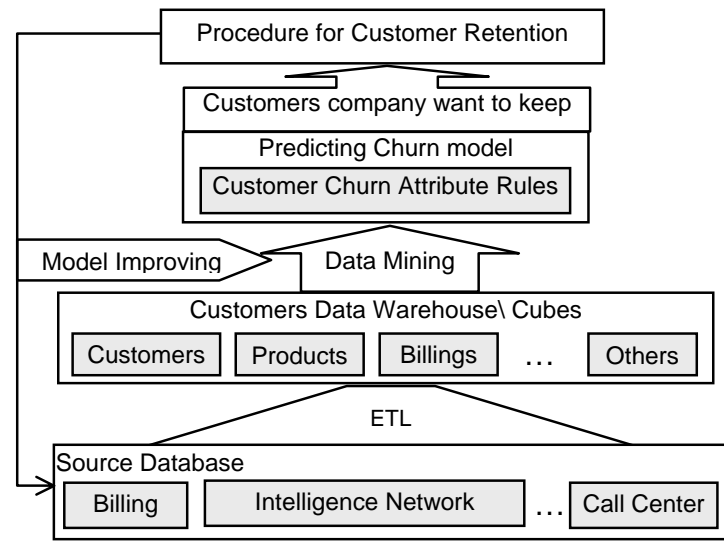

Fig. 1:The Customer Retention System Model

Source Database come from Operation Support System (OSS) in telecom companies, including the billing system, wireless intelligence network system, call center system and SMS platform system and so on. The Customers Data Warehouse (CDW) was built up through data Extraction, Transformation and Loading (ETL) from the Source Database. The CDW is built based on Dimension Data Model (DDM). The fact tables include billing data and information etc. and dimension tables include customer, product data and information etc.

The key component in the system is the predicting customer churn model. It will be discussed in detail through a case of a telecom company in China in the next section.

\section{A Customer Churn Model for a Telecom Company in China}

\subsection{The Model Objective and Conditions}

OBJECTIVE: The objective in this case is to gain knowledge of customer churn over the time of customer tenure and identify the customers who are at high risk of churn and when they would churn by the customer churn model. And help the company to deploy retention strategies.

TIME WINDOWS: It took 6 months for modeling in which 3 months for training, 1 month for testing, 2 months for evaluation, i.e. the model was built up based on customer behaviors in 3 continuous months and used to predict the customer churn in next month.

DEFINITIONS: This section clarifies some of the important concepts used in this case.

Churn - In the telecom industry, the broad definition of churn is the action that a customer's telecom service is canceled or hung. This includes both service-provider initiated churn and customer initiated churn. An example of service-provider initiated churn is a customer's account being closed because of payment default. Customer initiated churn is more complicated and the reasons behind vary. Examples of reasons are: unacceptable call quality, more favorable competitor's pricing plan, misinformation given by sales, customer expectation not met, billing problem, moving, change in business, and so on..

Customers - Only customers who have received at least three monthly bills are considered in the case.

If a customer's first invoice covers less than 30 days of service, then the customer monthly revenue is prorated to a full month's revenue. This case does not include employee accounts and test accounts, since churn for employee accounts and test accounts is not of a problem or an interest for the company.

Granularity - This case examines customer churn at the account level. 
DATA SOURCES: There are three major data sources for the system: customer level demographic data, customer internal data, and customer contact records. A brief description of some of the data sources follows.

Demographic Data - In our system, the following are examples of customer level demographic information: Name, Birthday and age, Gender, Dwelling, and so on.

Customer Internal Data - Customer internal data is from the CDW. It consists of two parts. The first part is about customer information like market channel, plan type, bill agency, customer segmentation code, ownership of the company's other products, dispute, late fee charge, discount, promotion/save promotion, additional lines, toll free services, rewards redemption, billing dispute, and so on. The second part of customer internal data is customer's telecom usage data. Examples of customer usage variables are:

- Weekly average call counts

- Percentage change of minutes

- Share of domestic/international revenue

Customer Contact Records - The Company's Customer Information System (CIS) stores detailed records of customer contacts. This basically includes customer calls to service centers and the company's mail contacts to customers. The customer contact records are then classified into customer contact categories, such as customer general inquiry, customer requests to change service, customer inquiry about cancel, and so on.

SAMPLING STRATEGY: On June 1, 2004, a sample of 40,000 active customers was randomly selected from the entire customer base from the telecom company. All customers were followed for the next 6 months. Therefore June 1, 2004 is the origin of time and December 31, 2004 is the observation termination time. During this 6-month observation period, the timing of customer churn was recorded.

\subsection{Modeling Principle}

The principle of the model shows as fig 2:

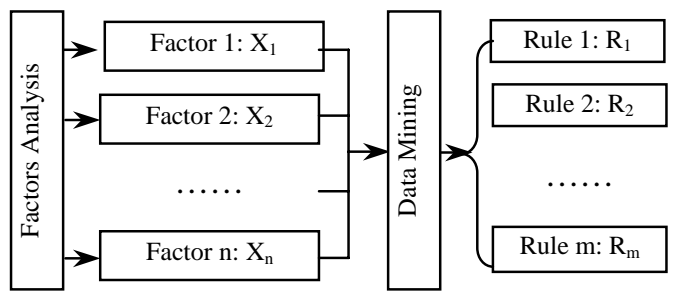

Fig. 2:The Principle of the Model Building

The factors (variables) will be selected by factors analysis. These factors are the main influence to the problem definition, i.e. customer retention in this case. They may be the direct observed variables or middle statistical variables. The influence power criterion for these factors as below:

The bigger customers churn probability under factor i will be more power to affect to the customer retention.

So, the $\mathrm{t}_{0}$ will be got when $\mathrm{CP}_{\mathrm{i}}\left(\mathrm{t}_{0}\right)=\max \left(\mathrm{CP}_{\mathrm{i}}(\mathrm{t})\right)$,

Here, $t_{0}, t$ represent customer tenure (days) and $0<\mathrm{t}, \mathrm{t}_{0}<92 . \mathrm{CP}_{\mathrm{i}}(\mathrm{t})=\mathrm{NC}_{\mathrm{i}}(\mathrm{t}) / \mathrm{AC}$, it means the customer churn probability under Factor i. $\mathrm{NC}_{\mathrm{i}}$ are Numbers of customer churn under Factor i. AC are all customers during the observation period for model built (3 months).

The factors will be segmented as three predicting levels by $t_{0}$ under factor $i$ when $t_{0}$ was got. The first level factors will be defined as $0<t_{0}<=7$. The second level will be defined as $7<t_{0}<=14$. The third level will be as $14<\mathrm{t}_{0}<=92$. The levels show the urgent level.

Using machine learning \data mining algorithm to different levels, we got the rules about the knowledge of customer churn.

\subsection{Modeling Process}

Model process includes the following major steps Explanatory Data Analysis (EDA) Explanatory data analysis was conducted to prepare the data for the customer churn analysis. An univariate frequency analysis was used to pinpoint value distributions, missing values and outliers. Variable transformation was conducted for some necessary numerical variables to reduce the level of skewness, because transformations are helpful to improve the fit of a model to the data. Outliers are filtered to exclude observations, such as outliers or other extreme values that are suggested not to be included in the data mining analysis. Filtering extreme values from the training data tends to produce better models because the parameter estimates are more stable. Variables with missing values are not a big issue, except for those demographic variables. The demographic variables with more than $20 \%$ of missing values were eliminated. For observations with missing values, one choice is to use incomplete observations, but that may lead to ignore useful information from the variables that have non-missing values. It may also bias the sample since observations that have missing values may have other things in common as well. Therefore, in this study, missing values were replaced by appropriate methods. For interval variables, replacement values were calculated based on the random percentiles of the variable's distribution, i.e., values were assigned based on the probability distribution of the non-missing observations. Missing 
values for class variables were replaced with the most frequent values (count or mode).

Variable reduction - Started with 110 variables in the original data set, by using an initial univariate analysis of all categorical variables crossed with customer churn probability was carried out to determine the statistically significant categorical variables to be included in the next modeling step. All the categorical variables with a chi-square value or $t$ statistics of 0.05 or less were kept. This step reduced the number of variables to 61 - including all the numerical variables and the kept categorical variables from the above step.

The next step is to further reduce the number of variables. A stepwise selection method was used to create a final model with statistically significant effects of 29 exploratory variables on customer churn over time.

\section{Model Results}

The following will be given the first level predicting factors model as an example. It is a result of the factor analysis.

Note 1: N/A means not acceptance

Note 2: $\star$ means 1 star. $i$ is half of a star.

5 stars mean the highest power influence to the customer churn.

\begin{tabular}{|c|c|c|c|}
\hline Factors & Description & $\begin{array}{l}\text { Power } \\
\text { level }\end{array}$ & $\begin{array}{l}\text { Advice } \\
\text { Value }\end{array}$ \\
\hline OCO & $\begin{array}{c}\text { One or more } \\
\text { services canceled } \mathrm{N} \\
\text { days by customer } \\
\text { order }\end{array}$ & $\begin{array}{l}\star \star \\
\star \star \star\end{array}$ & $\mathrm{N}=1$ \\
\hline CIS & $\begin{array}{l}\text { Customers initiated } \\
\text { stop calls N days }\end{array}$ & $\begin{array}{l}\star \star \\
\star \lesssim\end{array}$ & $\mathrm{N}=2$ \\
\hline ACR & $\begin{array}{l}\text { Account closed } \mathrm{N} \\
\text { days by customers } \\
\text { requirement }\end{array}$ & $\begin{array}{l}\star \star \\
\star \Sigma\end{array}$ & $\mathrm{N}=2$ \\
\hline HCL & $\begin{array}{l}\text { Services hung due } \\
\text { to credit level alert }\end{array}$ & $\stackrel{\star}{\star}$ & $\mathrm{N}=7$ \\
\hline CWB & $\begin{array}{l}\text { Continuous } \mathrm{N} \text { days } \\
\text { without bills }\end{array}$ & $\begin{array}{c}\star \star \\
i\end{array}$ & $\mathrm{~N}=7$ \\
\hline CPD & $\begin{array}{c}\text { Closed due to } \\
\text { payment default } \mathrm{N} \\
\text { days }\end{array}$ & $\star$ & N/A \\
\hline CFC & $\begin{array}{c}\text { Continuous } \\
\text { forward calls to } \\
\text { competitor } \mathrm{N} \text { days }\end{array}$ & $\star$ & N/A \\
\hline CRC & $\begin{array}{c}\text { Charges reduce } \\
\text { Continuously N } \\
\text { days with over M } \\
\%\end{array}$ & $\star$ & N/A \\
\hline
\end{tabular}

By applying machine learning $\backslash$ Data Mining analysis to the different customer segment, the models will be built. And the customers to which the company deserves to perform its customer retention strategies were obtained.

\section{Conclusion}

In this paper, the customer retention system based on intelligence was introduced. The Machine Learning Data Mining techniques provided a powerful tool to predict customer churn. By using the rules to predict customers churn, the system will help telecom companies understand customer churn risk and get the list of customers deserved to perform company's retention strategies. Overall, the system is helpful in customizing marketing communications and customer treatment programs to optimally time their marketing intervention efforts.

\section{References}

[1] Qilong wang, $2^{\text {nd }}$ China Telecom Industry

Business Intelligence conference, Sep14-16, 2005, www.billingchina.com/meeting/bi2005a/speaker0 9.asp.

[2] Machine Learning, Tom Mitchell, McGraw Hill, 1997.

[3] Advance Marketing Consultant, The Value Of Customer Retention: A Business Without A Customer Retention Plan Will Lose Revenue And Market Share, 2006, www.marketingprinciples.com/customerretention.

[4] Rob Mattison, Telecom churn Management Customer Telecare Series, Apdg Publishing, April 1, 2001

[5] Lu, Junxiang, Detecting Churn Triggers for Early Life Customers in the Telecom Industry - An Applications of Interactive Tree Training, Proceedings of the 2nd Data Mining Conference of DiaMondSUG 2001, Chicago, IL, 2001.

[6] Rud, Olivia Parr, Data Mining Cookbook, New York: John Wiley \& Sons, 2001.

[7] Smith Tyler and Besa Smith, Survival Analysis and the Application of Cox's Proportional Hazard Modeling 